\title{
Intramedullary Osteoid Osteoma: Two Cases Reports and Review of
} Literature

\author{
Badiaa. Bannar ${ }^{*}$, F. Jaafari, Z. Btissam, D. Basraoui, H. Jalal
}

Radiology service mother and child hospital CHU Mohammed VI Faculty of Medicine and Pharmacy of Marrakech Morocco

DOI: $10.36347 /$ sjmcr.2021.v09i04.017

| Received: 06.03.2021 | Accepted: 24.03.2021 | Published: 22.04.2021

*Corresponding author: Badiaa Bannar

\section{Abstract}

Osteoid osteoma is a benign primary bone tumor. This tumor is relatively common, represents $12 \%$ of all benign bone tumors and about 2 to $3 \%$ of all bone tumors. We report two new cases of histologically confirmed intramedullary osteoid osteoma. In 8-year-old and 9-year-old girls who consulted for chronic intermittent pain in the left leg onset, and worsened over time with discreet swelling in relation to the whole evolving in a context of apyrexia and conservation of the general condition, the two patients underwent a satandard X-ray, CT and MRI of the left leg.

Keywords: Osteoid osteoma, intramedullary CT, MRI.

Copyright (C) 2021 The Author(s): This is an open-access article distributed under the terms of the Creative Commons Attribution 4.0 International License (CC BY-NC 4.0) which permits unrestricted use, distribution, and reproduction in any medium for non-commercial use provided the original author and source are credited.

\section{INTRODUCTION}

Medullary osteoid osteoma is a very exceptional location. The origin of reactive osteogenesis has been linked to localized hemodynamic changes in the form of medullary venous stasis and stimulation of periosteal venous return.

\section{FIRST OBSERVATION}

We report the case of an 8-year-old girl with a history of trauma to the left lower limb who presents for pain with decreased use of the left lower limb. Initially, the pain was intermittent and mild; however, it increased.

On examination the girl was in good health with slight swelling over the left leg. The local temperature and the overlying skin were normal.

There was no difference in the length of the limbs, his biological assessment was normal and it was completed by an X-ray which showed cortical thickening of the tibial shaft (Fig. 1.a).

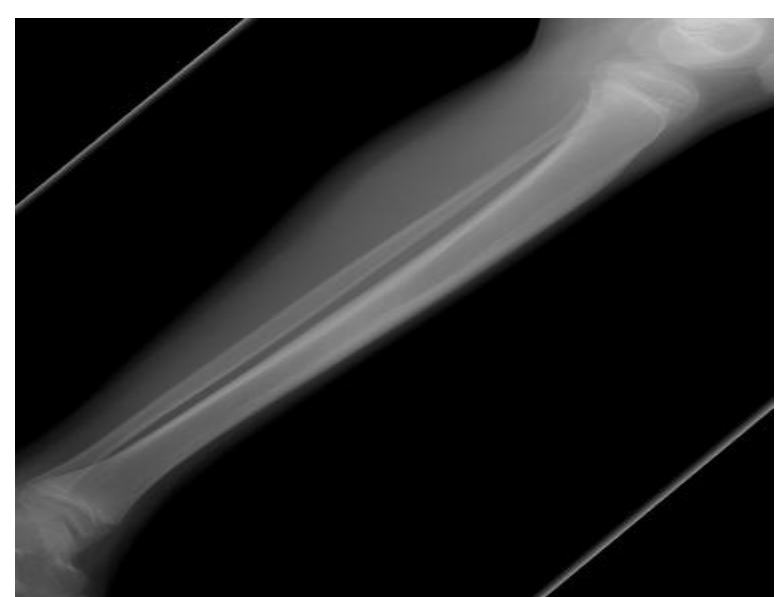

Fig-1.a

The patient was put on amoxicillin without improvement with persistence of the symptoms; hence the need for additional CT scans which demonstrated a frosted glass appearance of the middle third of the tibia with a neighboring periosteal reaction in axial and coronal section (Fig. 1.b). 

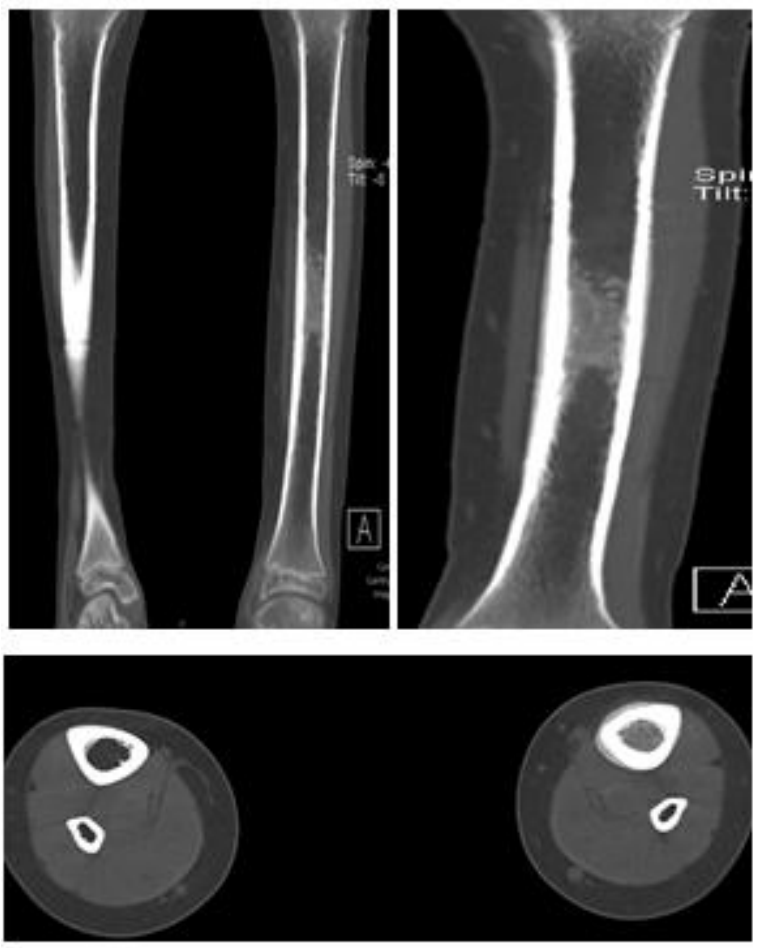

Fig-1.b
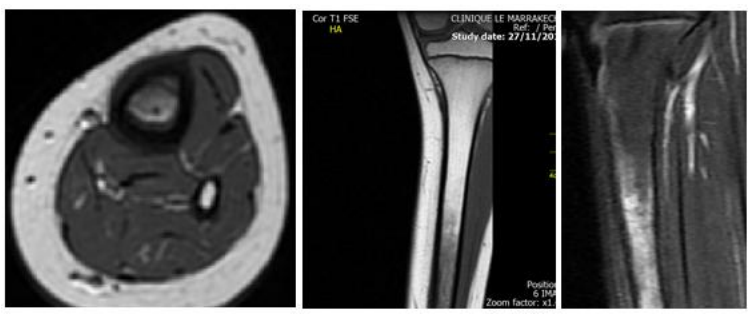

Fig-1.c

MRI of the left leg in axial T1, coronal T1 and sagittal STIR sequence: left tibial intramedullary bone edema with slight infiltration of neighboring soft parts and unilamellar bone reaction opposite.

\section{SECOND OBSERVATION}

A 9-year-old girl with no particular pathological history who presented to the emergency room for chronic pain in the left leg for two years which worsened recently, without deformity of the limb, all evolving in a context of apyrexia and of preservation of the general condition.

On clinical examination we noted a tenderness in relation to the left leg, the biological assessment was correct our patient received an X-ray of the left leg without any notable abnormality, an additional CT scan (Fig. 2.a) and a MRI (Fig. 2.b) were performed.

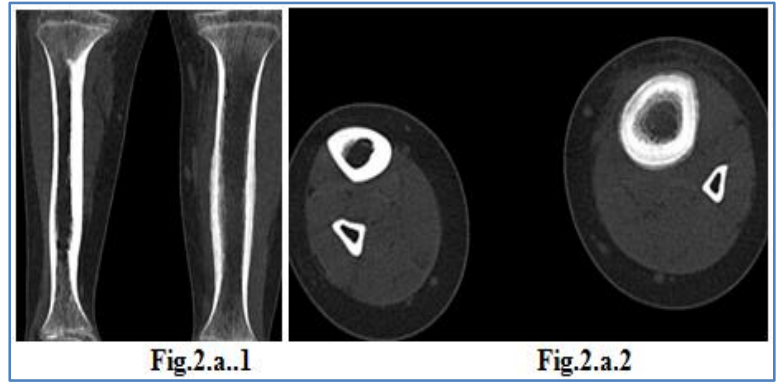

CT of the left leg in bone window in bone window axial cut (Fig.2.a.1) and coronal (Fig.2.a.2) objectifying a full and homogeneous unilamellar periosteal rection without rupture of the cortical opposite.

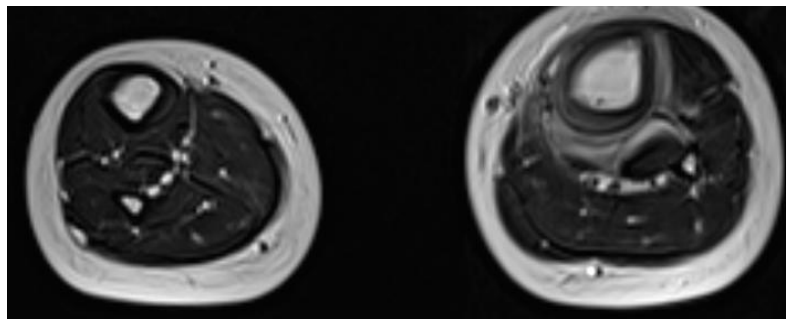

Fig-3.a.1

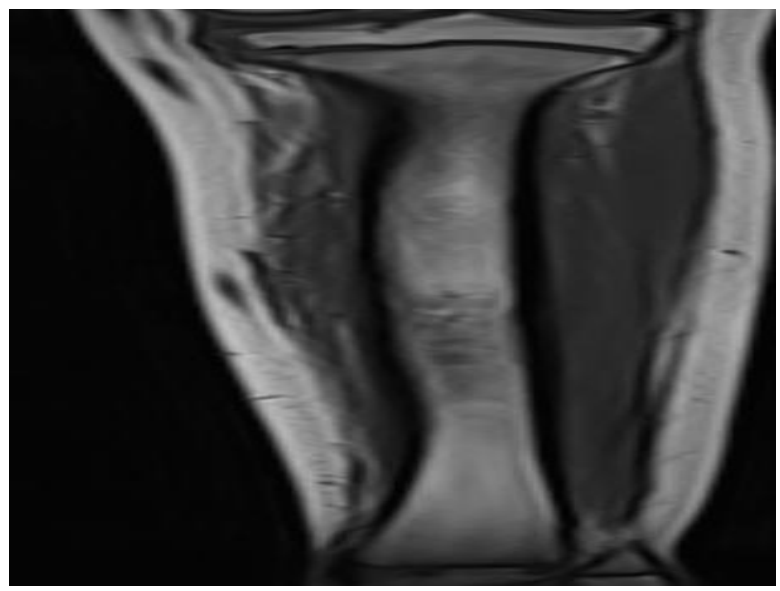

Fig-3.a.2

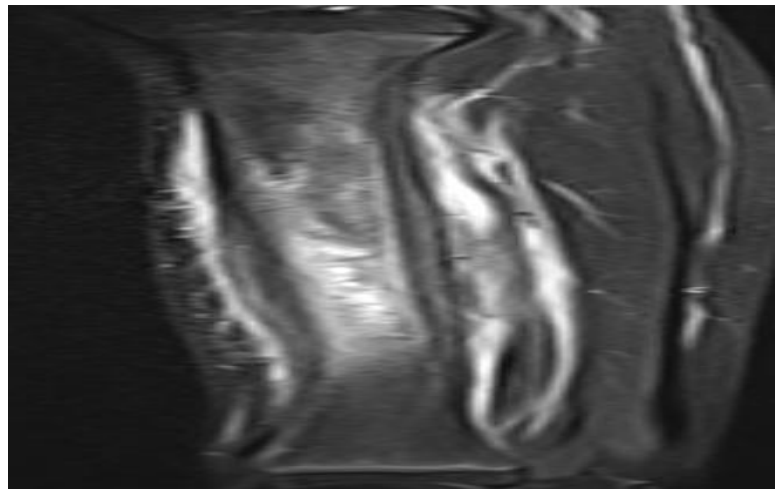

Fig-3.a.3 
Badiaa. Bannar et al., Sch J Med Case Rep, Apr, 2021; 9(4): 364-366

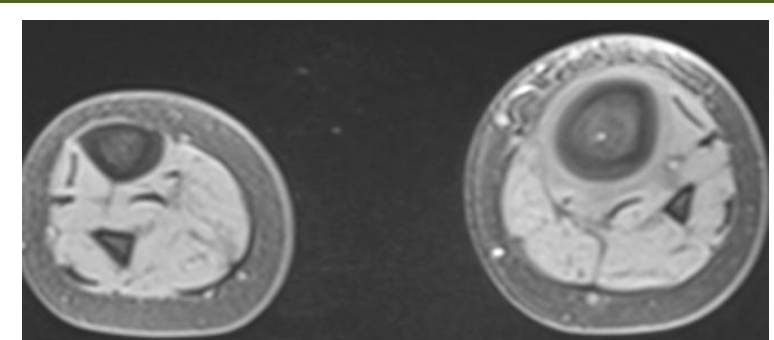

Fig-3.a.4

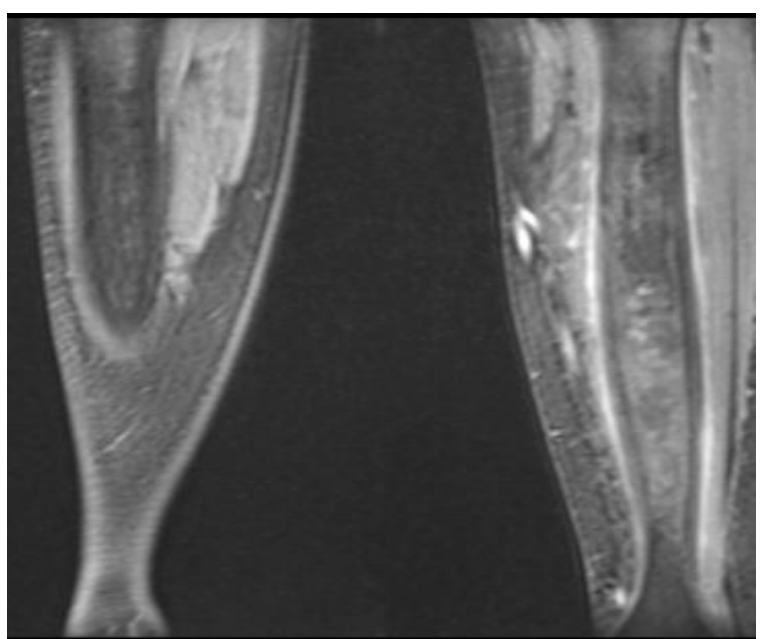

Fig-3.a.5

MRI of the left leg in axial section, and coronal having demonstrated signal abnormalities in the intramedullary area of the middle third of the left tibial shaft in T1 hyposignal (Fig.3.a.1 and Fig.3.a.2) hypersignal T2STIR (Fig3.a..3) enhancing heterogeneously after injection of the PDC (Fig.3.a.4 and Fig.3.a.5).

Edematous infiltration of the cortical bone without detectable rupture associated with a full homogeneous and unilateral periosteal reaction.

\section{Evolution}

Our two patients benefited from a complete surgical removal of the nidus which is the preferred treatment in children to prevent bone deformities, deviations in limb length and recurrences the postoperative consequences were simple without complications.

\section{DiscusSION}

Osteoid osteoma occurs very rarely in children under one year of age. Restlessness, inability to sleep at night, decreased use of the affected limb are signs reported in children suspected of having osteoid osteoma $[1,2]$.
Three types of osteoid osteoma based on the radiographic location of the nidus have been described in the literature: cortical (if the nidus is in the cortex), subperiosteal (if the nidus is located outside the cortex, surrounded by reaction periosteum) and intramedullary (if the nidus is located inside the medullary cavity). Intramedullary osteoid osteoma (also called cancellous) is relatively rare [3].

In our two patients, the nidus was localized intramedullary, which was a diagnostic challenge because the typical radiographic finding of the zone of central lucidity (nidus) and sclerosis of the surrounding bone tissue was minimal. Computed tomography is considered the best investigation to locate the nidus and confirm the diagnosis of osteoid osteoma. The tumor nidus can be difficult to identify on MRI, but MRI is a better method to characterize intramedullary edema and characterize the periosteal reaction and sometimes even rule out differential diagnoses [4].

The presentation of intramedullary osteoid osteomas is often confused with Ewing's sarcoma and with osteomyelitis.

CT-guided percutaneous radiofrequency thermal ablation is considered the treatment of choice for osteoid osteoma. Its role in the management of intramedullary osteoid osteoma is still under evaluation [5].

\section{CONCLUSION}

Complete surgical removal of the nidus is the preferred treatment in children to prevent bone deformities, limb length deviations and recurrence.

\section{REFERENCES}

1. Habermann ET, Stern RE. Osteoid-osteoma of the tibia in an eight-month-old boy: A case report. JBJS. 1974; 56:633-6.

2. Sherman MS. Osteoid osteoma: Review of the literature and report of thirty cases. JBJS. 1947;29:918-30

3. S Gupta, S Sinha, A Narang, and RK Kanojia Intramedullary osteoid osteoma in an 11-monthold child, J Postgrad Med. 2020 Jan-Mar

4. Sherman MS. Osteoid osteoma: Review of the literature and report of thirty cases. JBJS. 1947;29:918-30

5. Virayavanich W, Singh R, O'Donnell RJ, Horvai AE, Goldsby RE, Link TM. Osteoid osteoma of the femur in a 7-month-old infant treated with radiofrequency Radiol. 2010;39:1145-9 ablation. Skeletal 